\title{
Scaling up the provision of family planning messages in antenatal and postpartum services in Upper Egypt
}

Nahla G. Abdel-Tawab

Population Council

Sally Saher

Population Council

Follow this and additional works at: https://knowledgecommons.popcouncil.org/departments_sbsr-rh

Part of the Health Policy Commons, International Public Health Commons, Maternal and Child Health Commons, Obstetrics and Gynecology Commons, Public Health Education and Promotion Commons, and the Women's Health Commons

How does access to this work benefit you? Let us know!

\section{Recommended Citation}

Abdel-Tawab, Nahla G. and Sally Saher. 2011. "Scaling up the provision of family planning messages in antenatal and postpartum services in Upper Egypt," Extending Service Delivery Final Report. Cairo:

Population Council. 
FINAL REPORT

Scaling up the provision of family planning messages in antenatal and postpartum services in Upper Egypt

\author{
Dr. Nahla Abdel-Tawab \\ Dr. Sally Saher
}

June 2011 


\section{CONTENTS}

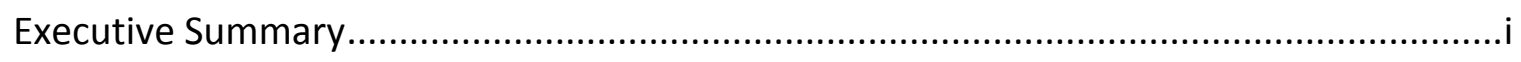

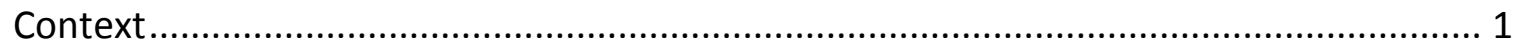

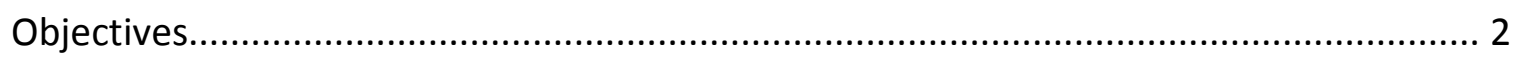

Intervention components ..................................................................................... 3

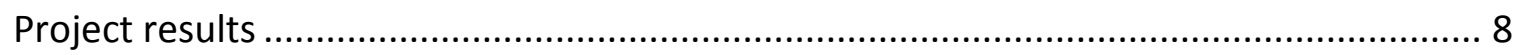

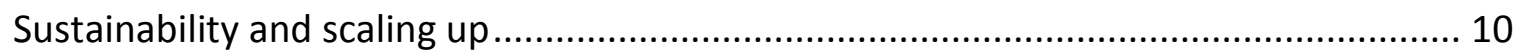

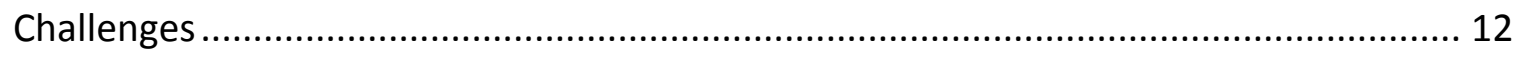

Recommendations and lessons learned ............................................................... 13

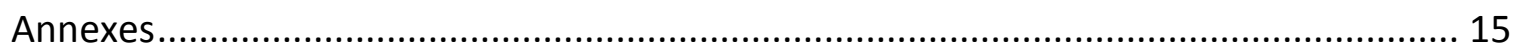




\section{EXECUTIVE SUMMARY}

An OR study by Population Council's FRONTIERS program, in 20 facilities in Assiut and Sohag governorates, showed integration of birth spacing messages into antenatal and postpartum care was feasible, acceptable to women and their husbands, and was associated with increased postpartum contraception. This intervention was scaled up into the entire governorates of Assiut and Sohag with funds from ESD/USAID. Scaling up activities occurred in two phases (June 2009 through November 2010, and December 2010 through April 2011). Phase I involved scaling up in eight districts in Assiut and Sohag, while phase II scaled up the intervention into remaining districts and built MoHP capacity for scaling up in other governorates. This report describes these phases, their outcomes, challenges, and recommendations for improvement.

Scaling up activities included: (a) revising and updating birth spacing messages protocol for pregnant and postpartum women; (b) training of trainers (TOTs) for FP and MCH managers and supervisors; (c) on the job training (OJT) of clinic staff (doctors, nurses and RRs); (d) providing IEC materials for clients and job aids for providers; (e) monitoring and supervision by MoHP and PC staff; ( $f$ ) seminars for husbands; (g) steering committee meetings; and (h) a national orientation and dissemination workshop. Implementing activities under phase I proceeded as planned, while those in phase II were delayed or modified as a result of the Egyptian revolution and subsequent strikes by health care providers.

This project was successful in scaling up the intervention in a total of eight districts in Assiut and Sohag and created conditions for scaling up in remaining 16 districts within those two governorates, as well as other governorates. Activities involved a total of 543 facilities in Assiut and Sohag, exceeding the initial target of 394. More than three quarters of managers and supervisors, and two thirds of pregnant and postpartum women, are aware of Healthy Timing and Spacing of Pregnancy and the three LAM criteria. In addition, there has been an increase of 25 to 47 percent in FP service utilization in the eight districts of Sohag and Assiut.

Our main achievement, however, is securing support and investment of senior MoHP officials at the central level, as well as support and commitment of managers and supervisors at governorate and district levels. Moreover, partnerships with other CAs (e.g. Takamol and CHL projects) and with USAID mission have been instrumental in influencing service delivery guidelines in favor of HTSP and standardizing messages across projects.

It is expected MoHP will take this intervention to a national level. With the current political situation and concern over negative reactions against FP, adopting the HTSP approach for providing FP messages may prove more useful and politically acceptable. While this project has set the stage for scaling up in other governorates, more needs to be done in assisting MoHP's adoption and integration of HTSP messages in different programs (e.g. pre service training, ANC, postpartum care and others). 


\section{CONTEXT}

A substantial proportion of women in Egypt experience unplanned pregnancies. According to the 2005 Egypt Demographic and Health Survey (EDHS), in the preceding five year period, about one in five births (19 percent) were not wanted at conception, while about half of births in Egypt occurred less than three years after previous birth (El-Zanaty and Way, 2006).

Postpartum use of contraception could prevent unplanned and closely spaced pregnancies. Many women, however, do not use contraception after birth because they (or their families) are not aware of health risks of short birth intervals; they use LAM incorrectly; or they lack correct information on FP methods or have concerns and misconceptions about contraceptive side effects.

Antenatal and postpartum periods are crucial times for information and counseling about birth spacing and postpartum use of contraception, since most women are in contact with the health care system during those periods. Provision of this type of information, however, often does not take place because $\mathrm{MCH}$ and FP services are segregated in the Egyptian health care system.

To address this need, Population Council's Frontiers in Reproductive Health Program (FRONTIERS), with funds from USAID, conducted an operations research study testing feasibility, acceptability, and effectiveness of providing birth spacing and FP messages to low parity women in Assiut and Sohag governorates, which are among the most conservative governorates in Egypt, wherein large families, son preference, and short birth intervals prevail.

The FRONTIERS OR study tested two models of integrating birth spacing messages in antenatal and postpartum care. The first model involved providing birth spacing and FP messages to low parity pregnant and postpartum women during antenatal and postpartum care services, while the second model comprised the same messaging plus an awareness raising IEC component targeting husbands and community leaders. This intervention was implemented in four districts in Assiut and Sohag governorates, with five facilities per district, thus in a total of 20 health facilities and surrounding villages. Additionally, one district per governorate served as a control (i.e. provided standard antenatal and postpartum care).

This first intervention was associated with increased use of postpartum contraception at 10 to 12 months postpartum (48 percent under Model I, 42 percent under Model II, compared to 31 percent in the control group). The intervention was also associated with increased utilization of FP services by low parity women (36 percent increase for Model I, 47 percent increase for Model II, versus three percent increase in control clinics; Abdel-Tawab et al., 2008).

Based those results and requests from senior Assiut and Sohag health officials, Population Council scaled up a modified version of Model II into additional districts in Assiut and Sohag 
governorates. Scaling up, implemented in two phases, was implemented by MoHP staff from central office, health directorates, and health districts with technical assistance from Population Council and funds from Extending Service Delivery Project (ESD/USAID). Phase I was implemented between June 2009 and November 2010 and involved four districts in each of the two governorates, with six clinics per district (i.e. a total of 48 clinics). ${ }^{1}$ Phase II involved scaling up into remaining districts in Assiut and Sohag (9 and 7 districts respectively) and creating conditions for scaling up to a national level. Phase II activities, which were planned to be implemented between December 2010 and April 2011, however, were delayed due to the revolution in Egypt and subsequent strikes among different occupational groups including health care providers. This report provides an overview of scaling up activities in phases I and II, challenges, lessons, and recommendations for sustainability and scaling up to national level.

\section{OBJECTIVES}

The overall objective of this activity was assisting the Government of Egypt in integrating birth spacing and FP messages into antenatal and postpartum services, with ultimate goal of helping Egyptian women achieve healthy birth intervals and avoid unplanned or closely spaced pregnancies.

\section{Specific objectives}

1. Assisting officials in Assiut and Sohag governorates in introducing the birth spacing intervention package into more districts and health facilities within Sohag and Assiut governorates;

2. Building capacity of managers and supervisors and health care providers in Assiut and Sohag governorates in counseling of pregnant and postpartum women on birth spacing, correct LAM use, and postpartum contraception;

3. Improving postpartum women's knowledge, attitudes, and practices regarding birth spacing, breastfeeding, and postpartum use of contraception, including LAM;

4. Mainstreaming birth spacing and postpartum FP messages into antenatal and postpartum care services nationwide.

\footnotetext{
${ }^{1}$ Although phase I was initially planned to cover a total of 48 clinics, managers and supervisors in those districts trained staff in more facilities, hence the intervention was scaled up to a total of 197 facilities during that phase.
} 


\section{INTERVENTION COMPONENTS}

A modified version of the initial intervention was implemented in the governorates of Assiut and Sohag. The modified intervention included:

\section{Birth spacing message protocol}

The new intervention targeted all pregnant and postpartum women (as opposed to low parity women) in Assiut and Sohag. Messages included healthy timing and spacing of pregnancy, birth spacing advantages, effective LAM use, postpartum contraception, and time of fertility return after delivery (for breastfeeding and non-breastfeeding mothers), and importance of Day 30 visit to clinics. These messages were delivered to pregnant women during third trimester ANC visits to clinics, to postpartum women during

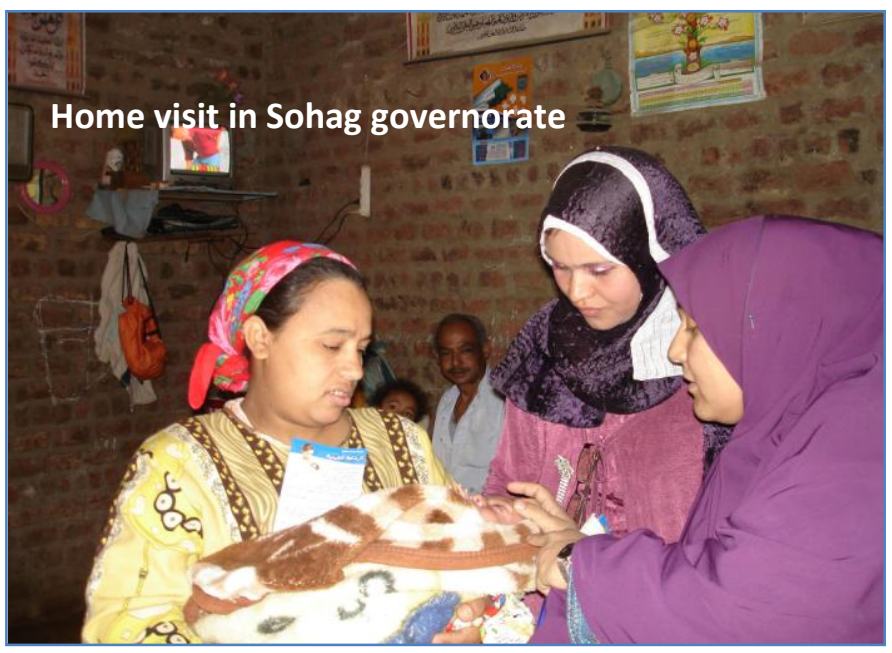
home visits, and at Day 30 postpartum visits to clinics.

The home visit protocol included a total of four postpartum home visits (day 2 and day 4 by $\mathrm{MCH}$ nurse alone, day 7 by nurse and $R R$ together, day 21 by $R R$ alone). ${ }^{2}$ This protocol has one less visit than the one tested in the pilot study (day 1 , day 2 , day 7 , day 14 , and day 21 ): The day 14 visit was dropped as it was found redundant. During PP home visits, nurses check on health of mothers and newborns and looks for warning signs, while $R R \mathrm{~s}$ provide health education and information on HTSP. In addition, nurses and RRs exchange findings of visits and inform doctors of any warning signs requiring follow up. It is worth mentioning existing MoHP guidelines required more home visits ( 5 home visits by $\mathrm{MCH}$ nurse and one visit by the $R R$ ) and did not require coordination between the two providers.

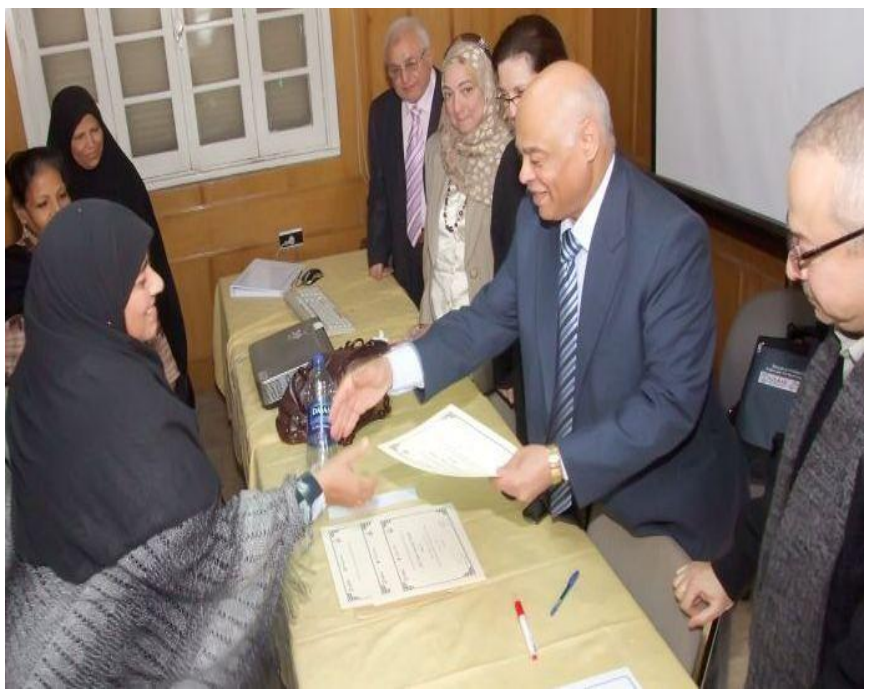

One of the participants at Sohag ToT workshop receiving a certificate from Sohag Health

\footnotetext{
${ }^{2} R R$ (Raeda Rifya) is an FP outreach worker.
} 
The Day 30 visit component involved comprehensive services to mother and newborn at the first postpartum visit to the clinic. ${ }^{3}$ Services provided on that visit include physical assessment of mother and newborn, ascertaining newborn immunization status, health education about breastfeeding, nutrition, hygiene, as well as FP services and counseling about HTSP.

\section{Training of trainers (TOT)}

FP and $\mathrm{MCH}$ managers and supervisors in all Assiut and Sohag districts received ToT on intervention components and implementation monitoring. A total of seven three-day workshops in phases I and II ( 2 in phase I and 5 in phase II) included a total of 192 participants (65 in phase I and 127 in phase II). Workshop participants included district manager, FP manager, $\mathrm{MCH}$ manager, FP nurse supervisor, $\mathrm{MCH}$ nurse supervisor, $R R$ supervisor, and IEC officer, while trainers were governorate level managers and supervisors and central office staff trained under the pilot project. Training covered: (a) definition of HTSP and advantages of birth spacing; (b) antenatal care; (c) postpartum home visits; (c) postpartum FP methods; (d) Day 30 postpartum visit; (e) principles of informed and voluntary FP choice; (e) on the job training; and (f) monitoring and supervision. These workshops combined oral presentations, case studies, role plays, and brainstorming exercises. A copy of the workshop training agenda is attached in the Appendix.

Existing training materials developed in the FRONTIERS Birth Spacing intervention were updated and used. Additional updates in phase II used material from the HTSP training manual, HTSP Counseling Pathways (ESD), and PP FP manual (ACCESS FP project). Hand outs for some sessions were updated, as well as case studies, scenarios for role plays, and pre- and post tests.

\section{On the job training (OJT)}

The initial pilot project included off-site training for all clinic staff, but it was found cost ineffective due to rapid staff turnover, so was replaced with on the job training (OJT) during scaling up, for enhancing sustainability. District managers and supervisors attending ToT conducted OJT for staff in clinics within their districts. OJT covered the same topics as ToT (i.e. HTSP, advantages of birth spacing, integrating birth spacing messages into antenatal and postpartum care, postpartum FP methods, and principles of informed and voluntary choice in FP). The district team provided clinic staff with service delivery protocols for antenatal postpartum care as well as checklists assisting their counseling of clients during antenatal and postpartum care. In a few districts, the district team chose to bring in staff from several clinics to the district conference room for training. A total of 1,931 providers received OJT in Assiut and Sohag in phase I, and 2,170 in phase II.

\footnotetext{
${ }^{3}$ Traditionally this visit was recommended to take place at six weeks postpartum but as it was noted that some women were already pregnant by that time, hence it was agreed with MOHP officials to move it up to day 30.
} 


\section{IEC materials}

IEC materials and job aids from previous Population Council projects were used in scaling up activities, besides new IEC materials specifically designed for the scaling up project. CHL provided Population Council with reprints of materials developed under the pilot project, while material developed specifically for this project was printed by Population Council with ESD/ USAID funds. A copy of each IEC material is attached in the Annexes.

- Birth spacing flier: This flier was developed collaboratively with CHL project in the pilot phase. Key messages highlighted in the flier include healthy birth interval (minimum of three years), criteria for effective LAM use, postpartum methods of contraception, and what to do in case of side-effects. This flier was given to mothers during ANC, postpartum home visits, and to husbands during community seminars.

- LAM Frequently Asked Questions sheet: This sheet had been developed collaboratively by Population Council and CHL project under the FRONTIERS project to assist providers in counseling clients about breastfeeding and LAM use. The FAQ sheet was distributed to all clinics in Assiut and Sohag, with each provider receiving one copy for his/her reference. Reprints for phase I were made by $\mathrm{CHL}$, while those for phase II were by PC.

- Breastfeeding /LAM flier: This flier, which was developed collaboratively by FRONTIERS and $\mathrm{CHL}$, provides information to clients on adequate breastfeeding practices and correct LAM use. Copies of this flier were given to mothers during ANC and postpartum home visits, and to husbands during seminars.

- Day $\mathbf{4 0}$ visit wall chart: This job aid was developed by Population Council in the pilot project for reminding clinic staff of services to be offered to mothers and newborns during the day 40 postpartum visit. The chart also helps clients know what services to expect during that visit, and to demand those services. The chart illustrates different providers seeing mothers during the Day 40 visit, and the role of each one. A copy of this wall chart is displayed in the waiting area of all facilities in Assiut and Sohag.

- Postpartum visits manual for nurses and RRs: This manual provides rationale for each postpartum home visit (day 2, 4, 7 and 21) and outlines tasks (including health education messages) of nurses and RRs on each home visit. It was developed in phase II for combating inadequate home visits noted in phase I. Copies were sent to Assiut and Sohag facilities, as well as district and governorate managers and supervisors. Additional copies will be sent to MoHP central office for distributing to priority governorates 
in Upper Egypt (Minya, Qena and Beni Suef) and to selected governorates in Lower Egypt (Qalubeya and Dakahleya).

- Poster for counseling clients about birth spacing: This poster was developed by Population Council in phase II because, in earlier phases, birth spacing counseling was given as a fixed script to all clients, regardless of their intentions or needs. This poster, based on the HTSP Counseling Pathways manual, is designed to assist nurses in counseling women who are pregnant, postpartum, or with a child less than two years, about birth spacing. Copies of this poster

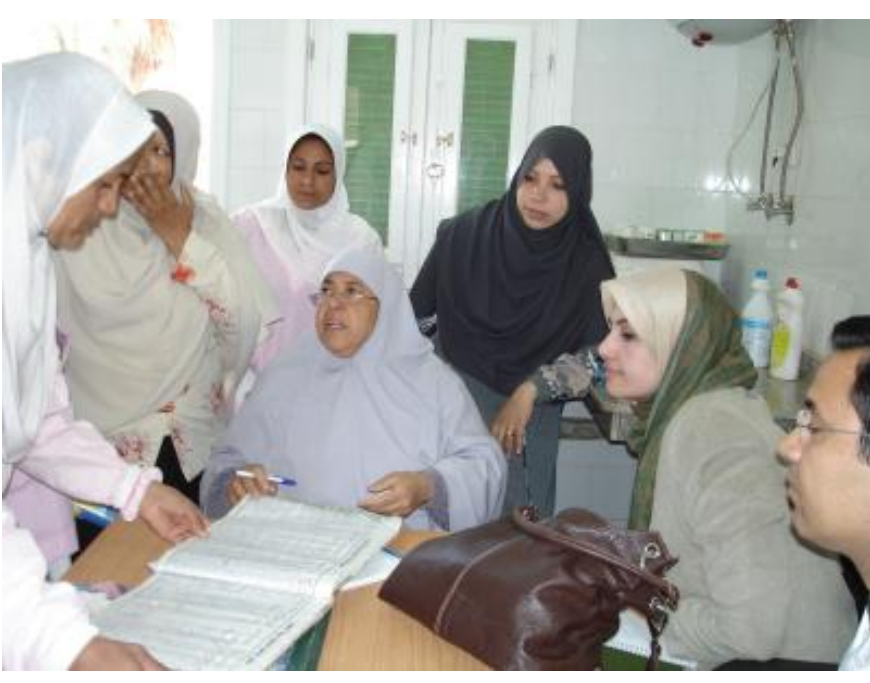

Monitoring visit by MoHP and PC staff to clinic in Assiut have been sent to all facilities in Assiut and Sohag, while additional copies will be sent to MoHP central office for distributing to other governorates.

\section{Monitoring and supervision}

District managers and supervisors monitored scaling up activities by conducting monthly visits to scaling up clinics as well as governorate managers and supervisors, who conducted quarterly visits. Each visit included both a manager or supervisor from MCH and FP who used monitoring checklists specifically designed for this project. PC and MoHP staff (central office) conducted additional visits. On each monitoring visit the team visited three to four facilities, conducting interviews with staff, reviewing log books, conducting home interviews with pregnant or postpartum women, and holding briefing meetings with district and governorate managers and supervisors. In briefing meetings, districts managers and supervisors discussed plans for staff OJT with governorate managers and proposed solutions for overcoming scaling up obstacles within districts. The governorate undersecretary also indicated plans for mobilizing resources for supporting further scaling up within the governorate. A total of 10 monitoring visits was conducted under phases I and II (9 and 1, respectively). Monitoring visits by PC staff were reduced in the scaling up project, for MoHP to take more responsibility for those activities.

Home interviews each month with a sample of pregnant or postpartum women monitored quality of counseling services for women who visited clinics for antenatal care or received postpartum home visits. In addition, those interviews assessed women's knowledge, attitudes, 
and practices regarding birth spacing and PP contraceptive use (including LAM). Data collectors were recruited from Sohag and Assiut health directorates, but they were not affiliated with $\mathrm{MCH}$ or FP departments. 1,440 interviews were conducted in phase I. No interviews were conducted in phase II, for security reasons.

Finally, data on FP service utilization was collected from all 48 clinics participating in phase I, for measuring

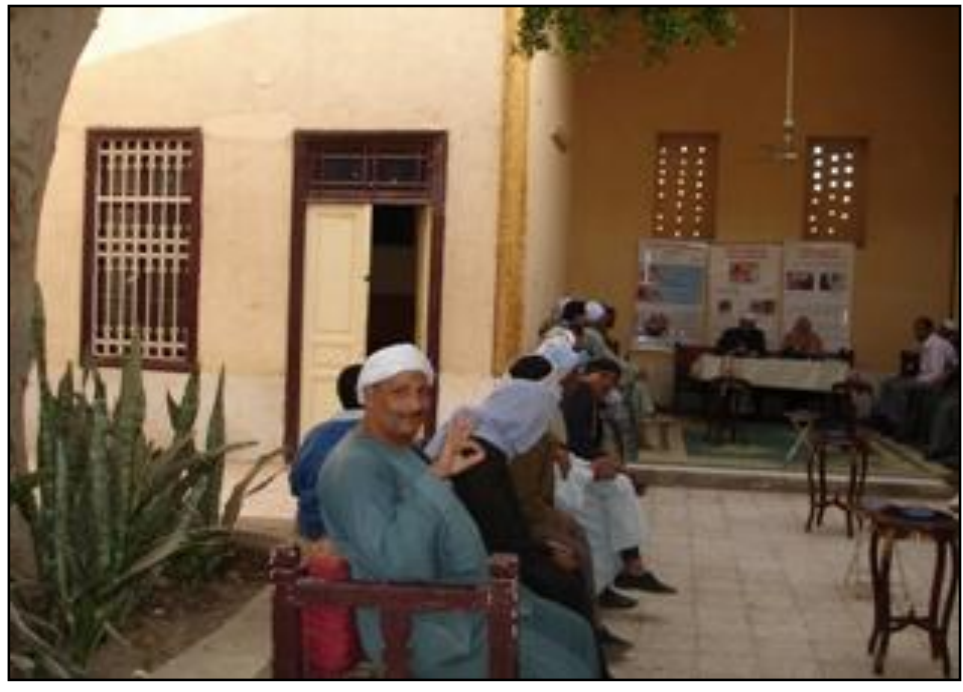

Seminar for husbands in Assiut percent increase in FP service utilization during intervention compared to six months before intervention. No such data was collected in phase II, as we did not expect any change in service utilization, given the phase's short duration and the political circumstances, which affected implementation of scaling up activities.

\section{Seminars for men}

In phase I, seminars for men in each scaling up village were assisted by the district IEC officer. In these seminars, clinic doctors talked about birth spacing benefits for mothers, children and families, importance of postpartum contraception, and types of FP methods, including LAM. The religious leader discussed benefits of birth spacing from a religious point of view, as well as men's responsibility for their families' health. The two speakers then answered questions. A total of 48 seminars were held in phase I, with an average of 30 to 40 participants in each one. Security concerns precluded holding seminars in phase II.

\section{Steering committee meetings}

A project steering committee of senior MoHP officials and PC staff met every quarter for reviewing project progress and agreeing on possible changes in policies or guidelines as well as a strategy for scaling up to other governorates. The committee was composed of FP and $\mathrm{MCH}$ undersecretaries, $\mathrm{MCH}$ Director, Principal Investigator (PC), and Project Coordinator (PC), with 10 meetings over the life of the project, eight during phase I and two during phase II. The steering committee met more often during the scaling up project compared to the pilot phase, for setting strategies for institutionalization. 


\section{National orientation /}

dissemination workshop

This workshop in phase II (April 1618 , 2011) introduced officials in other governorates, as well as MoHP central office staff, to the intervention components and encouraged replication intervention in other governorates (workshop agenda is attached). The workshop was attended by 74 participants representing 29 governorates, as well as senior central office staff $(\mathrm{MCH}$

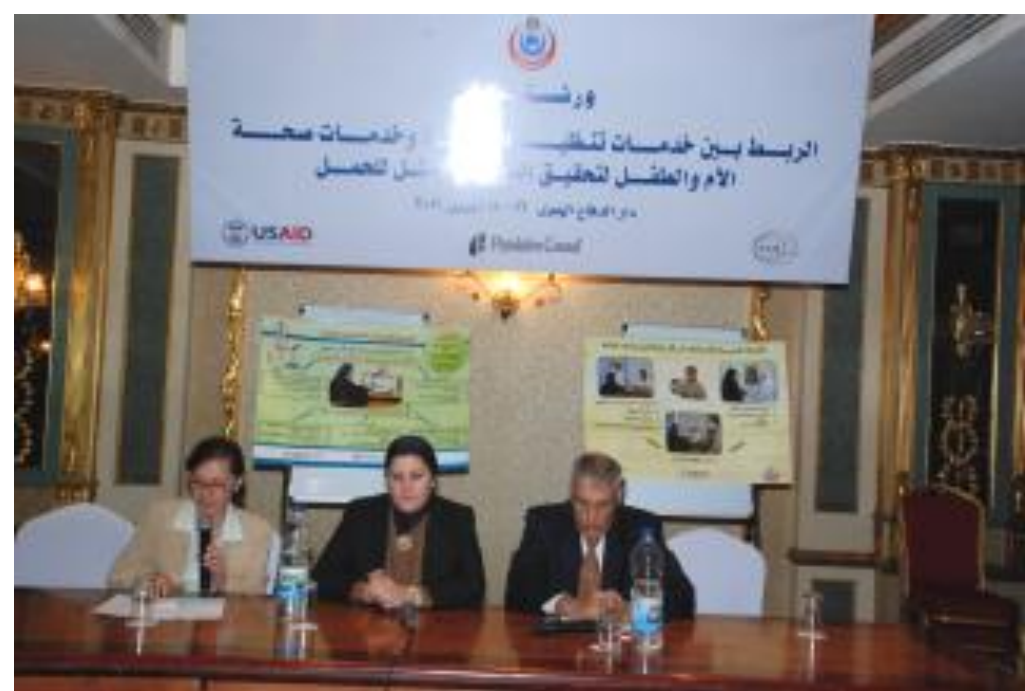

Opening session at dissemination/orientation workshop April 6-8, 2011 and FP). Participants from Assiut and Sohag presented challenges and lessons from implementing the intervention. At the end of the workshop, $\mathrm{MCH}$ and FP directors from each governorate developed a work plan for scaling up within their governorates. Each participant received a folder with copies of power point presentations, reading materials, IEC materials, two CDs with the updated training curriculum (trainee and trainer manuals), as well as manuals for nurses and $R R$ s for enabling reprints of those materials within their governorates.

\section{PROJECT RESULTS}

This project was successful in scaling up the intervention into a total of eight districts in Assiut and Sohag and created conditions for scaling up in remaining districts within those two governorates, as well as other governorates in Egypt. Table 1 shows quantitative achievements, namely number of staff receiving ToT, OJT, and knowledge acquired among managers, and supervisors, and women in phases I and II. As previously mentioned, the short duration of phase II, combined with political circumstances, did not allow enough time for monitoring implementation of scaling up activities in phase II. According to governorate and district managers, OJT was provided to all staff in 16 scaling up districts; however, we could not ascertain if HTSP messages were actually provided to clients served by those providers. 
Table 1: Quantitative achievements (Phase I \& II)

\begin{tabular}{|l|c|c|c|c|c|c|}
\hline \multirow{2}{*}{ Indicators } & \multicolumn{3}{|c|}{ Phase one } & \multicolumn{3}{c|}{ Phase two } \\
\cline { 2 - 8 } & Target & Achiev. & $\begin{array}{c}\% \\
\text { Achiev. }\end{array}$ & Target & Achiev. & $\begin{array}{c}\% \\
\text { Achiev. }\end{array}$ \\
\hline \# of villages / clinics covered with intervention & 48 & 197 & 410 & $346^{4}$ & 346 & 100 \\
\hline \# of managers / supervisors who received ToT & 56 & 63 & 112 & 128 & 127 & 100 \\
\hline \# of providers who received OJT & 288 & 1,951 & 677 & $2,170^{5}$ & 2,170 & 100 \\
\hline $\begin{array}{l}\text { Percent managers / supervisors who knew } \\
\text { about HTSP }\end{array}$ & 100 & 100 & 100 & 100 & 85 & 85 \\
\hline $\begin{array}{l}\text { Percent managers / supervisors who knew } \\
\text { criteria for LAM }\end{array}$ & 100 & 87 & 87 & 100 & 81 & 81 \\
\hline $\begin{array}{l}\text { Percent of ANC clients who received } \\
\text { information on birth spacing }\end{array}$ & 100 & 89 & 89 & $90^{6}$ & - & - \\
\hline $\begin{array}{l}\text { Percent of ANC clients who know three criteria } \\
\text { for LAM }\end{array}$ & 100 & 60 & 60 & 65 & - & - \\
\hline $\begin{array}{l}\text { Percent of PP women who know three criteria } \\
\text { for LAM }\end{array}$ & 100 & 70 & 70 & 65 & - & - \\
\hline $\begin{array}{l}\text { Percent of postpartum women who received } 4 \\
\text { PP home visits }\end{array}$ & 100 & 38 & 38 & 50 & - & - \\
\hline $\begin{array}{l}\text { Percent of managers and supervisors in } \\
\text { additional four governorates who received } \\
\text { HTSP }\end{array}$ & - & - & - & $100^{7}$ & & \begin{tabular}{c} 
Senior officials in MoHP \\
\hline $\begin{array}{l}\text { Mainstreaming HTSP into national service } \\
\text { delivery guidelines }\end{array}$
\end{tabular} \\
\hline $\begin{array}{l}\text { Percent increase in utilization of FP services } \\
\text { headquarters approved birth } \\
\text { spacing/PPFP protocol for } \\
\text { national use }\end{array}$ \\
\hline
\end{tabular}

It is noteworthy that, despite political circumstances, implementing OJT activities in phase II proceeded at a faster rate than phase I, as supervisors gained more experience and confidence. Also, publicity given to this intervention through the dissemination/orientation workshop and local media made officials in Assiut and Sohag more committed to implementing the intervention in the best possible manner and demonstrating good results.

\footnotetext{
${ }^{4}$ This figure pertains to the clinics in the 16 scaling up districts.

${ }^{5}$ This figure is smaller than the one mentioned in the proposal because the latter assumed that each clinic has 6 providers. The actual number of providers in the 16 scaling up districts is 2,170.

${ }^{6}$ Home interviews with a random sample of pregnant/postpartum women were not conducted in phase II for security reasons

${ }^{7}$ MoHP did not receive funds for scaling in four governorates, hence this activity was replaced by a dissemination/orientation workshop for FP\&MCH managers from 29 governorates.

${ }^{8}$ Clinic utilization data were not planned to be collected in phase II due to short duration of that phase.
} 
Our main achievement during this project is securing support and investment by senior MoHP officials at the central level. Through regular meetings and information from field visits, we have increased their interest and engagement. With their support, we were able to address problems at district level (e.g. actions against managers and supervisors not making monitoring visits). The FP undersecretary, who is very supportive of the intervention, presented this project as a "Best Practice" at the Implementing Best Practices workshop organized by the WHO regional office, in June 2010 in Rabat. She also applied for funds from the Government of Egypt and WHO/EMRO for scaling up this intervention in four additional governorates.

We worked with MoHP central office and cooperating agencies (CAs) to introduce changes in service protocols, aiding integration of services. For example, we convinced MoHP officials to move the first PP clinic visit up to Day 30. This way, a woman's baby can be immunized against TB (BCG vaccine) and she can receive PP FP services on the same visit. This also protects nonbreastfeeding women from unplanned pregnancy, as some are reported to ovulate as early as fourth week postpartum. We have also requested the Day 30 visit include services for newborns (growth monitoring and immunization) and mother, even if she will not receive FP services. We were also successful in integrating birth spacing messages into the Integrated Standards of Practice (ISoP). We also managed to add $R R$ visits to the PP home visit schedule.

At governorate and district levels, we succeeded in eliciting support and commitment from the majority of managers and supervisors. District managers and supervisors during phase I not only covered OJT costs for providers in 48 clinics (e.g. transportation, staff time), but also many mangers in Assiut and Sohag expanded OJT activities to cover other clinics within their districts. During phase II all clinics in both Assiut and Sohag received OJT using local resources.

\section{SUSTAINABILITY AND SCALING UP}

These project activities enhanced sustainability and potential for national scale up:

1. The modified intervention package is simple, suitable for resource-poor settings, and can be implemented with existing government resources. It did not add a significant burden on health care providers. It is in keeping with MoHP policies and is based on local and international best practices.

2. Postpartum home visits were kept to a minimum to prevent overburdening $\mathrm{MCH}$ nurses and RRs. 
3. $\mathrm{MCH}$ nurses and RRs were not paid any incentives, nor transportation costs, for home visits ensuring scale up and sustainability. Neither $\mathrm{MCH}$ nurses nor RRs received any monetary incentive for conducting these visits. In fact, the initial birth spacing study showed proper training, clear delineation of roles and responsibilities, and adequate supervision ensures nurses and $R R$ s can make the visits.

4. ToT was conducted by MoHP staff from central office, as well as health directorates. We concluded training by MoHP staff would ensure sustainability and scale up. Today we have a cadre of qualified trainers in all districts of Assiut and Sohag as well as MoHP central office.

5. Senior MoHP staff was involved in the conceptualization as well as implementation of the scaling up process, including monitoring of the intervention. In fact, the entire scaling up activity was implemented by MoHP staff in Assiut and Sohag with supervision and guidance from MoHP central office.

6. MoHP is covering some costs of scaling up (e.g. staff time, facilities, vehicles, and other support).

7. Partnering with other organizations (e.g. $\mathrm{CHL}$ and TAKAMOL) helped mainstream the intervention into national guidelines.

8. The dissemination/orientation workshop helped introduce FP and $\mathrm{MCH}$ managers in other governorates to the intervention components. Providing copies of the training manual as well as nurse and $R R$ home visit manual enables reprinting those materials based on immediate need.

9. Our long-term goal is assisting MoHP central office in integrating intervention components into the pre-service training course offered to newly graduating doctors before they join primary health care clinics.

10. We plan to work with the contractor of the upcoming USAID project and MoHP (central office) in scaling up the intervention into the governorates of Minia, Beni Suef and Qena, Qalyubeya and Dakahleya. We are currently coordinating with MoHP central office, ensuring delivery project IEC materials to those governorates. 


\section{CHALLENGES}

- The main challenge for this project was delay of phase II activity implementation as a result of the Egyptian Revolution and subsequent strikes by health care providers. Of greater concern, however, is revolution's potential effect on future FP/RH activities in Egypt. With the rise of Islamist groups and anti-Mubarak sentiment, FP may be losing priority on the national agenda. Ministry of Family and Population has been abolished, and the National Population Council is now under supervision of the Minister of Health, which, to some extent, reflects reduced interest in population issues. Adopting the HTSP approach in providing FP messages may prove useful, as using a demographic approach and emphasizing negative impact of population growth might be unacceptable.

- Some FP officials were concerned integrating birth spacing messages within $\mathrm{MCH}$ services would mean loss of territory for the FP sector, while some $\mathrm{MCH}$ officials were concerned this would overburden staff and divert attention from $\mathrm{MCH}$ services. Moreover, senior MoHP officials were reluctant to add a line item in clinic log books for newborn assessment and women's physical examination results from Day 30 (regardless of whether receiving an FP method). We reassured both officials that providing birth spacing or FP messages within antenatal or postpartum services would help, and strengthen, both sectors. We also explained that discussing birth spacing during antenatal care would not add more than five minutes to consultations but could help reduce maternal mortality by 30 percent, and infant mortality by 10 percent.

- High turnover among senior officials posed another challenge. Throughout the life of the project, the Assiut Undersecretary changed three times, while the FP Undersecretary changed once. Involvement of less senior MoHP officials (e.g. FP and MCH directors) in all phases enhanced our credibility and helped solicit support of incoming undersecretaries.

- Some MoHP managers and supervisors at governorate level had difficulty changing their mindsets and roles from intervention recipients to active implementers, hence they expected Population Council to conduct frequent monitoring visits and provide training for scaling up to additional sites. We repeatedly emphasized that in the scaling up phase, Population Council only provides TA and that primary responsibility for implementation and scaling up rests with MoHP. Support we received from central office staff helped convey this message. 


\section{RECOMMENDATIONS AND LESSONS LEARNED}

- This project succeeded in scaling up the intervention into eight districts in Assiut and Sohag, serving more than 70,000 pregnant and postpartum women. One key factor contributing to this project's success was high sense of ownership by MoHP staff at central office, health directorates, and health districts. This sense of ownership was built through regular meetings, continued feedback, and involvement of MoHP officials in planning and implementing all activities. As a result, they mobilized resources and pushed for scaling up in additional clinics within their districts.

- Building partnerships and coalitions is very important for policy change. We partnered with Takamol project and USAID mission to have services for mother and newborn on Day 30 included in updated service delivery guidelines, and we partnered with $\mathrm{CHL}$ for producing IEC materials. Besides saving costs, the $\mathrm{CHL}$ partnership helped standardize IEC messages in different projects.

- Scaling up an intervention often requires continued adaptation for emerging needs or unique features of each community. Examples of adaptations made in the project include reducing numbers of home visits, developing a home visit manual for nurses and $R R \mathrm{~s}$, adding a ToT session on informed and voluntary FP choice. These interventions may need further adaptation if implemented in urban areas without $R R$ s or in governorates like Qena, with a shortage of RRs. Continuous dialog between central and governorate officials help make right adaptations and ensure proper implementation.

- Finally, we need to acknowledge scaling up an intervention to a national level needs enough time and technical support. This project has created conditions for scaling up the intervention into other governorates in Upper and Lower Egypt by involving senior MoHP officials from central office, holding a dissemination/orientation workshop with managers and supervisors from 29 governorates, and making electronic copies of training and IEC materials available. Scaling up into other governorates demands continued follow-up by MoHP staff from central office, along with technical support from local and international organizations assisting adaption and integration of HTSP into different MoHP programs. We also recommend that the upcoming USAID-funded project, in Upper Egypt, includes a component for scaling up this intervention into those governorates. 


\section{ANNEXES}

Annex 1: Integration of family planning services with maternal and child health services in Assiut and Sohag

Training schedule

Training of Trainers, Assuit and Sohag, 2011

\begin{tabular}{|l|l|l|l|l|l|}
\hline Day & $\begin{array}{l}\text { First session } \\
9: 00-10: 45\end{array}$ & $\begin{array}{l}\text { Coffee Break } \\
10: 45-11: 00\end{array}$ & $\begin{array}{l}\text { Second } \\
\text { session } \\
11: 00-1: 00\end{array}$ & $\begin{array}{l}\text { Coffee Break } \\
1: 00-1: 30\end{array}$ & $\begin{array}{l}\text { Third session } \\
1: 30-3: 30\end{array}$ \\
\hline Day 1 & $\begin{array}{l}\text { Pre test, } \\
\text { Opening } \\
\text { remarks } \\
\text { Healthy } \\
\text { timing and } \\
\text { spacing of } \\
\text { pregnancy }\end{array}$ & & $\begin{array}{l}\text { Health } \\
\text { education in } \\
\text { antenatal } \\
\text { care }\end{array}$ & & $\begin{array}{l}\text { Postpartum } \\
\text { Home visits }\end{array}$ \\
& $\begin{array}{l}\text { Providing an } \\
\text { integrated } \\
\text { service during } \\
\text { Day 30 visit } \\
\text { to the clinic }\end{array}$ & & $\begin{array}{l}\text { Post-partum } \\
\text { family } \\
\text { planning } \\
\text { methods }\end{array}$ & & \\
\hline
\end{tabular}

\begin{tabular}{|l|l|l|l|l|l|}
\hline Day & $\begin{array}{l}\text { First session } \\
9: 00-10: 00\end{array}$ & $\begin{array}{l}\text { Coffee Break } \\
10: 00-10: 15\end{array}$ & $\begin{array}{l}\text { Second } \\
\text { session } \\
10: 15-1: 00\end{array}$ & $\begin{array}{l}\text { Coffee Break } \\
1: 00-1: 30\end{array}$ & $\begin{array}{l}\text { Third session } \\
1: 30-3: 30\end{array}$ \\
\hline Day 3 & $\begin{array}{l}\text { Pilot study in } \\
\text { Assiut and } \\
\text { Sohag }\end{array}$ & & $\begin{array}{l}\text { On the job } \\
\text { training } \\
\text { Sharing } \\
\text { experience of } \\
\text { pilot districts }\end{array}$ & $\begin{array}{l}\text { Monitoring } \\
\text { and } \\
\text { supervision }\end{array}$ & $\begin{array}{l}\text { Working } \\
\text { groups }\end{array}$ \\
& & & $\begin{array}{l}\text { Group } \\
\text { presentations } \\
\text { Post test } \\
\text { Course } \\
\text { evaluation } \\
\text { Closing } \\
\text { remarks }\end{array}$ \\
\hline
\end{tabular}




\section{Annex 2: Linking family planning services with maternal and child health to achieve healthy timing and spacing of pregnancy}

\section{Antenatal Care Checklist (third trimester)}

Governorate: District: Health unit: Pregnancy month:

\begin{tabular}{|c|c|c|c|c|}
\hline Serial & Health Service & Done & Not done & Not applicable \\
\hline 1 & Hemoglobin test & & & \\
\hline 2 & Urine sugar test & & & \\
\hline 3 & Albumin test & & & \\
\hline 4 & Rh for primiparas or those who have one child & & & \\
\hline 5 & Asking about the medical history & & & \\
\hline 6 & Measuring blood pressure correctly & & & \\
\hline 7 & Measuring weight correctly & & & \\
\hline 8 & Giving Tetanus vaccination / completing & & & \\
\hline 9 & Medical examination (by the doctor) & & & \\
\hline 10 & Health education on danger signs & & & \\
\hline 11 & Health education on nutrition & & & \\
\hline 12 & $\begin{array}{l}\text { Health education on the benefits of birth spacing for mother \& } \\
\text { infant in the } 3^{\text {rd }} \text { trimester }\end{array}$ & & & \\
\hline 13 & Health education on breast feeding in the $3^{\text {rd }}$ trimester & & & \\
\hline 14 & Health education on three criteria for LAM & & & \\
\hline 15 & Health education on return of fertility after delivery & & & \\
\hline 16 & Advice on how to get prepared for delivery & & & \\
\hline 17 & Postpartum family planning health education & & & \\
\hline 18 & Giving supplements as iron & & & \\
\hline 19 & Recording data in the health card & & & \\
\hline 20 & Confirming the next follow up date and giving IEC materials & & & \\
\hline 21 & Personal treatment of client & Poor & Moderate & Good \\
\hline 22 & $\begin{array}{l}\text { Source of data } \\
\begin{array}{ll}\text { 1. } & \text { Observation } \\
\text { 2. Client / provider interview } \\
\text { 3. } & \text { Review of medical records }\end{array}\end{array}$ & & & \\
\hline
\end{tabular}

\section{Supervisor's remarks}

1.

2.

\section{Supervisor's name:}

Occupation:
Doctor's / nurse name:

Date of visit: 


\section{Linking family planning services with maternal and child health to achieve healthy timing and spacing of pregnancy}

\section{Postpartum home visit checklist}

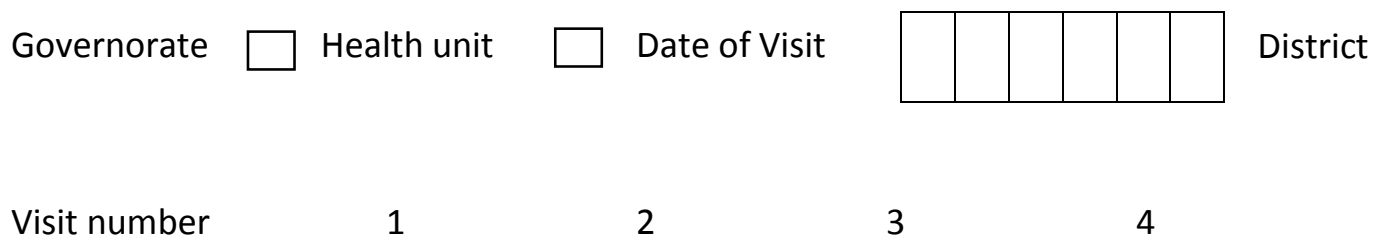

Total number of visits received by the mother

Who made the visit?

Number of visits

1. Nurse alone

2. Raeda alone

3. Nurse and Raeda together

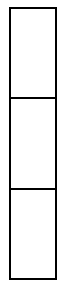

\begin{tabular}{|l|l|l|l|l|}
\hline Serial & Performance & Done & Not done & Not Applicable \\
\hline Mother Examination: & & & \\
\hline 1 & Measuring Temperature & & & \\
\hline 2 & Measuring blood pressure & & & \\
\hline 3 & Asking about vaginal discharge (amount-color-smell) & & & \\
\hline 4 & Breast examination & & & \\
\hline 5 & $\begin{array}{l}\text { Fundus examination (above umbilicus-between umbilicus and } \\
\text { symphysis) }\end{array}$ & & & \\
\hline 6 & Perineal examination (normal-wounds-pus) & & & \\
\hline 7 & Leg veins examination & & & \\
\hline Infant Examination: & & & \\
\hline 1 & Height-Weight & & & \\
\hline 2 & Umbilicus examination (normal-inflammation) & & & \\
\hline 3 & Neonatal Jaundice examination & & & \\
\hline 4 & Asking about: difficulty in breathing-cyanosis-convulsions & & & \\
\hline 5 & Making sure of the absence of obvious congenital defects & & & \\
\hline 6 & Asking about breast feeding & & & \\
\hline Health Education: & Nutrition education & & & \\
\hline 1 & Education about personal hygiene & & & \\
\hline 2 & Education about physical exercise & & \\
\hline 3 & Education about HTSP & & \\
\hline 4 & & & \\
\hline
\end{tabular}




\begin{tabular}{|c|c|c|c|c|}
\hline 5 & Education about breast feeding & & & \\
\hline 6 & Education about Thyroid test & & & \\
\hline 7 & Education about vaccination schedule & & & \\
\hline 8 & Education on time of return of fertility after delivery & & & \\
\hline 9 & Education on the three criteria of LAM & & & \\
\hline 10 & Family planning counseling & & & \\
\hline 11 & Using of IEC materials & & & \\
\hline 12 & Giving supplements: vitamin A & & & \\
\hline 13 & Letting the woman know the date of the next visit & & & \\
\hline 14 & Importance of day 30 visit & & & \\
\hline 15 & Recording data in the mother and the child health card & & & \\
\hline \multicolumn{2}{|c|}{ Personal treatment of client } & Poor & Moderate & Good \\
\hline & $\begin{array}{l}\text { f data } \\
\text { Client interview } \\
\text { Observation } \\
\text { Medical records }\end{array}$ & & & \\
\hline
\end{tabular}

\section{Supervisor's remarks:}

\section{Supervisor's name:}

Nurse/ Raeda's name:

\section{Occupation:}




\section{Linking family planning services with maternal and child health to achieve healthy timing and spacing of pregnancy}

\section{Day 30 visit checklist}
Governorate:
District:
Health unit:
Date of delivery:

Visit date:

\begin{tabular}{|l|l|l|l|l|}
\hline Serial $\quad$ Performance & Done & Not done & Not applicable \\
\hline Mother's health services: & & & \\
\hline 1 & Medical examination by the doctor & & & \\
\hline 2 & Health education on physical exercise & & & \\
\hline 3 & Health education on birth spacing & & & \\
\hline 4 & Health education on breast feeding & & & \\
\hline 5 & Health education on the three criteria for LAM & & & \\
\hline 6 & Health education on time of return of fertility after delivery & & \\
\hline 7 & Health education on nutrition & & & \\
\hline Infant's health services: & & & \\
\hline 1 & Height & & & \\
\hline 2 & Weight & & & \\
\hline 3 & Taking the necessary vaccination(BCG) & & & \\
\hline 4 & Making sure of the absence of obvious congenital defects & & & \\
\hline Family planning Services: & & & \\
\hline 1 & Family planning counseling & & & \\
\hline 2 & Provided family planning methods & & \\
\hline 3 & Type of method: & & & \\
\hline 4 & Directions on how to use the method & & \\
\hline 5 & Directions on the method's side effects & & \\
\hline 6 & Ensuring date of follow up visit-- in case of obtaining method & & & \\
\hline 7 & Giving the client IEC materials & & & \\
\hline Recording data in health card & & & \\
\hline Personal treatment of client & & \\
\hline Source of data & & & \\
\hline 1. Observation \\
3. Review of medical records
\end{tabular}

Supervisors' remarks:

1.

2.

Supervisor's name: Doctor's /nurse name:

\section{Occupation:}




\section{Annex 3: Linking family planning services with maternal and child health to achieve healthy timing and spacing of pregnancy}

Home Interview with pregnant women (7-9 months)

Serial \#

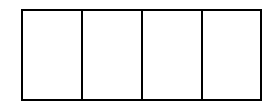

Interviewee Name:

Home Address:

Health Unit / Center:

Governorate: 1-Assiut ( ) 2-Sohag ( )

District: $\quad$ 1-Abo Teeg（） 2-ElBadary（） 3 -ElFateh（） 4 -Manfalout（ )

5-El Monshaa（） 6-Gerga（） 7-Sohag（） 8-Sakolta（ ）

Interview date: / / 2010

Interviewer's name:

Data on this questionnaire is confidential and should not be shared with anyone outside of Population Council team 


\section{Personal Data:}

\begin{tabular}{|c|c|c|c|c|c|}
\hline $1-$ & How many months are you pregnant? & & \multicolumn{2}{|l|}{ months } & $\square$ \\
\hline $2-$ & How many children do you have? & \multicolumn{3}{|c|}{$\begin{array}{lll}\text { 1-Girl } & \text { ( ) } & \text { number } \\
\text { 2-Boy } & \text { ( ) } & \text { number } \\
\text { 0-No children } & \end{array}$} & $\begin{array}{l}\text { Girl } \\
\text { Boy }\end{array}$ \\
\hline \multirow[t]{4}{*}{ 3- } & \multirow{4}{*}{$\begin{array}{l}\text { What are the three criteria that should be } \\
\text { fulfilled for breast feeding (LAM) to prevent } \\
\text { pregnancy? }\end{array}$} & & Mentioned & $\begin{array}{l}\text { Not } \\
\text { mentioned }\end{array}$ & \\
\hline & & $\begin{array}{l}\text { 1- During } 6 \text { months } \\
\text { from delivery }\end{array}$ & 1 & 2 & \\
\hline & & 2- No menses & 1 & 2 & \\
\hline & & $\begin{array}{l}\text { 4- Not giving any } \\
\text { external food or fluids } \\
\text { except breast milk }\end{array}$ & 1 & 2 & \\
\hline
\end{tabular}

\section{Health Services:}

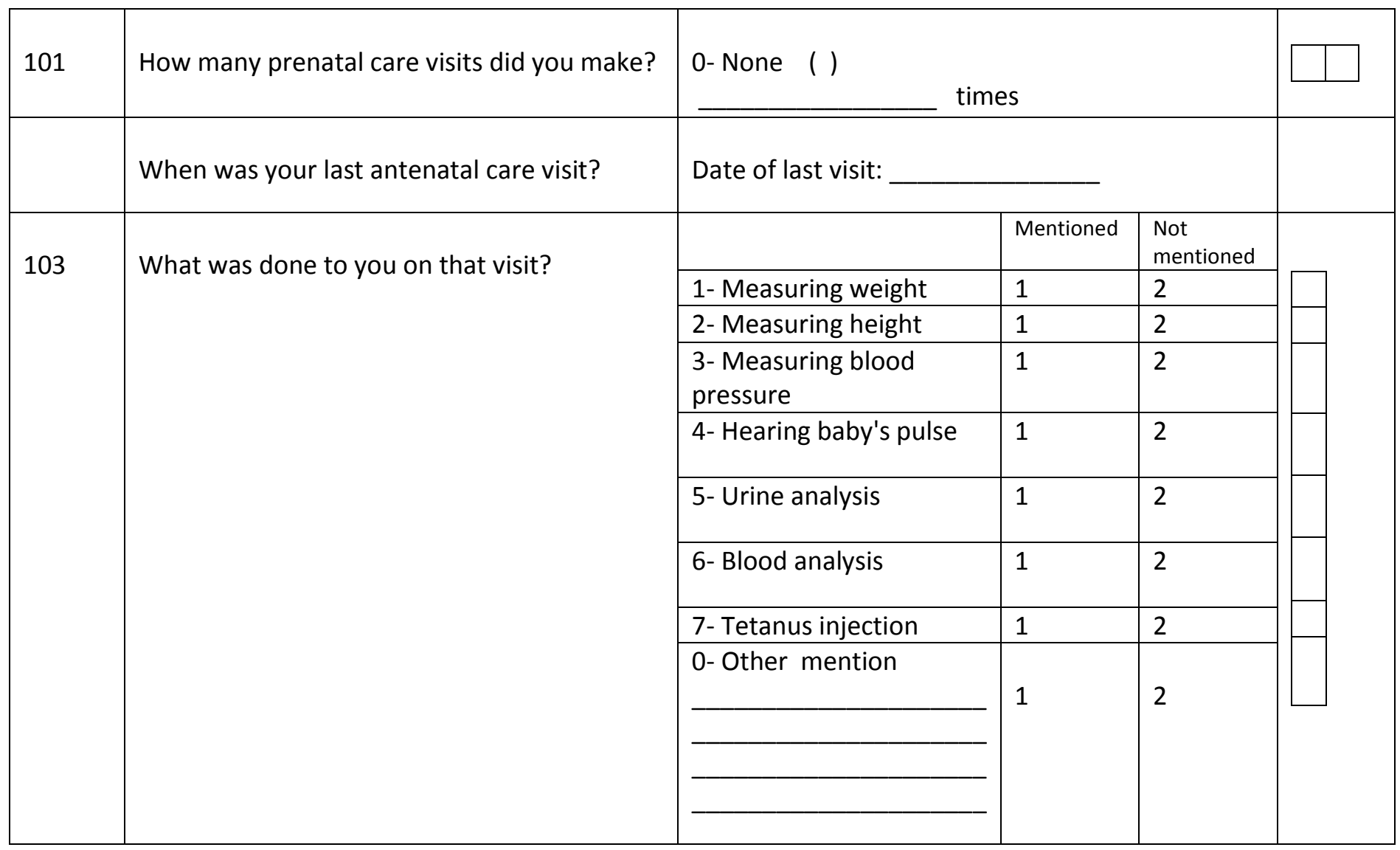




\begin{tabular}{|c|c|c|c|c|c|}
\hline 104 & $\begin{array}{l}\text { Did they talk with you about birth spacing } \\
\text { during that visit? }\end{array}$ & $\begin{array}{ll}1 & 1 \\
1 & 1\end{array}$ & go to $Q 106$ & & \\
\hline \multirow{6}{*}{105} & \multirow{6}{*}{ What did they say to you? } & & mentioned & Not mentioned & \\
\hline & & $\begin{array}{l}\text { 1- Birth spacing for } \\
3-5 \text { years }\end{array}$ & 1 & 2 & \\
\hline & & $\begin{array}{l}\text { 2- Birth spacing } \\
\text { importance and } \\
\text { benefits to mother } \\
\text { and infant }\end{array}$ & 1 & 2 & \\
\hline & & $\begin{array}{l}\text { 3- Breastfeeding } \\
\text { criteria as FP method }\end{array}$ & 1 & 2 & \\
\hline & & $\begin{array}{l}\text { 4- Take FP method by } \\
30^{\text {th }} \text { day }\end{array}$ & 1 & 2 & \\
\hline & & $\begin{array}{l}\text { 5- Suitable FP method } \\
\text { for breastfeeding }\end{array}$ & 1 & 2 & \\
\hline & & $\begin{array}{l}\text { 6- Time of return of } \\
\text { fertility after delivery }\end{array}$ & 1 & 2 & \\
\hline 106 & $\begin{array}{l}\text { Did they talk with you during the visit about } \\
\text { warning signs before labor? }\end{array}$ & \multicolumn{3}{|c|}{$\begin{array}{ll}\text { 1- Yes } & (1) \\
2-\text { No } & (1) \longrightarrow \text { go to } Q 108\end{array}$} & \\
\hline \multirow{8}{*}{107} & \multirow{8}{*}{ What warning signs did they mention to you? } & & mentioned & Not mentioned & \\
\hline & & 1- Bleeding & 1 & 2 & \\
\hline & & 2- Abdominal pain & 1 & 2 & \\
\hline & & 3- Convulsions & 1 & 2 & \\
\hline & & 4- Headache & 1 & 2 & \\
\hline & & 5- Blurring of vision & 1 & 2 & \\
\hline & & 6- Fever & 1 & 2 & \\
\hline & & 7- Water from vagina & 1 & 2 & \\
\hline 108 & $\begin{array}{l}\text { Did they tell you how to get prepared for } \\
\text { delivery? }\end{array}$ & \multicolumn{3}{|l|}{$\begin{array}{ll}1-Y e s & (1) \\
2-N o & (1)\end{array}$} & \\
\hline 109 & $\begin{array}{l}\text { Did they tell you about suitable family } \\
\text { planning methods after delivery? }\end{array}$ & \multicolumn{3}{|l|}{$\begin{array}{ll}1-Y e s & (1) \\
2-\text { No } & (1)\end{array}$} & \\
\hline \multirow[t]{7}{*}{110} & \multirow{7}{*}{ What methods they tell you about? } & & Mentioned & $\begin{array}{l}\text { Not } \\
\text { Mentioned }\end{array}$ & \\
\hline & & 1- IUD & 1 & 1 & \\
\hline & & 2- Breast feeding pills & 1 & 1 & \\
\hline & & 3- Injections & 1 & 1 & \\
\hline & & 4- Condoms & 1 & 1 & \\
\hline & & 5- Breast feeding & 1 & 1 & \\
\hline & & 0- Other mention & & & \\
\hline
\end{tabular}




\begin{tabular}{|c|c|c|c|c|}
\hline 111 & $\begin{array}{l}\text { Do you accept to stay for at least } 3 \text { years } \\
\text { before becoming pregnant again? }\end{array}$ & $\begin{array}{l}\text { 1- Yes } \\
2-\text { No }\end{array}$ & $\rightarrow$ go to $Q 113$ & \\
\hline 112 & $\begin{array}{l}\text { Would you accept to use a family planning } \\
\text { method by the } 30^{\text {th }} \text { day? }\end{array}$ & $\begin{array}{l}\text { 1- Accept } \\
\text { 2- Not accept }\end{array}$ & $(1)$ & 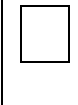 \\
\hline 113 & $\begin{array}{l}\text { In general what's your opinion about the } \\
\text { service you received at the clinic? }\end{array}$ & $\begin{array}{l}\text { 1- Good } \\
\text { 2- Average } \\
\text { 3- Not good }\end{array}$ & $\begin{array}{l}(1) \\
(1) \\
1 \quad\end{array}$ & $\square$ \\
\hline
\end{tabular}

Thank her and wish her a safe delivery.

Interviewer's comments: 


\section{Annex 4: Linking family planning services with maternal and child health to achieve healthy timing and spacing of pregnancy}

Home Interview for postpartum women (1 month after delivery)

Serial \#

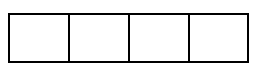

Mother's Name:

Home Address:

Health Unit / Group name:

Governerate: 1-Assiut ( ) 2-Sohag ( )

District: $\quad$ 1-Abo Teeg ( ) 2-ElBadary（） 3 -ElFateh ( ) 4 - Manfalout ( )

5- El Monshaa ( ) 6-Gerga ( ) 7-Sohag（） 8-Sakolta（ ）

Interview date: / / 2010

Interviewer's name:

Data on this questionnaire is confidential and should not be shared with anyone outside the Population Council team 


\section{I .Services received:}

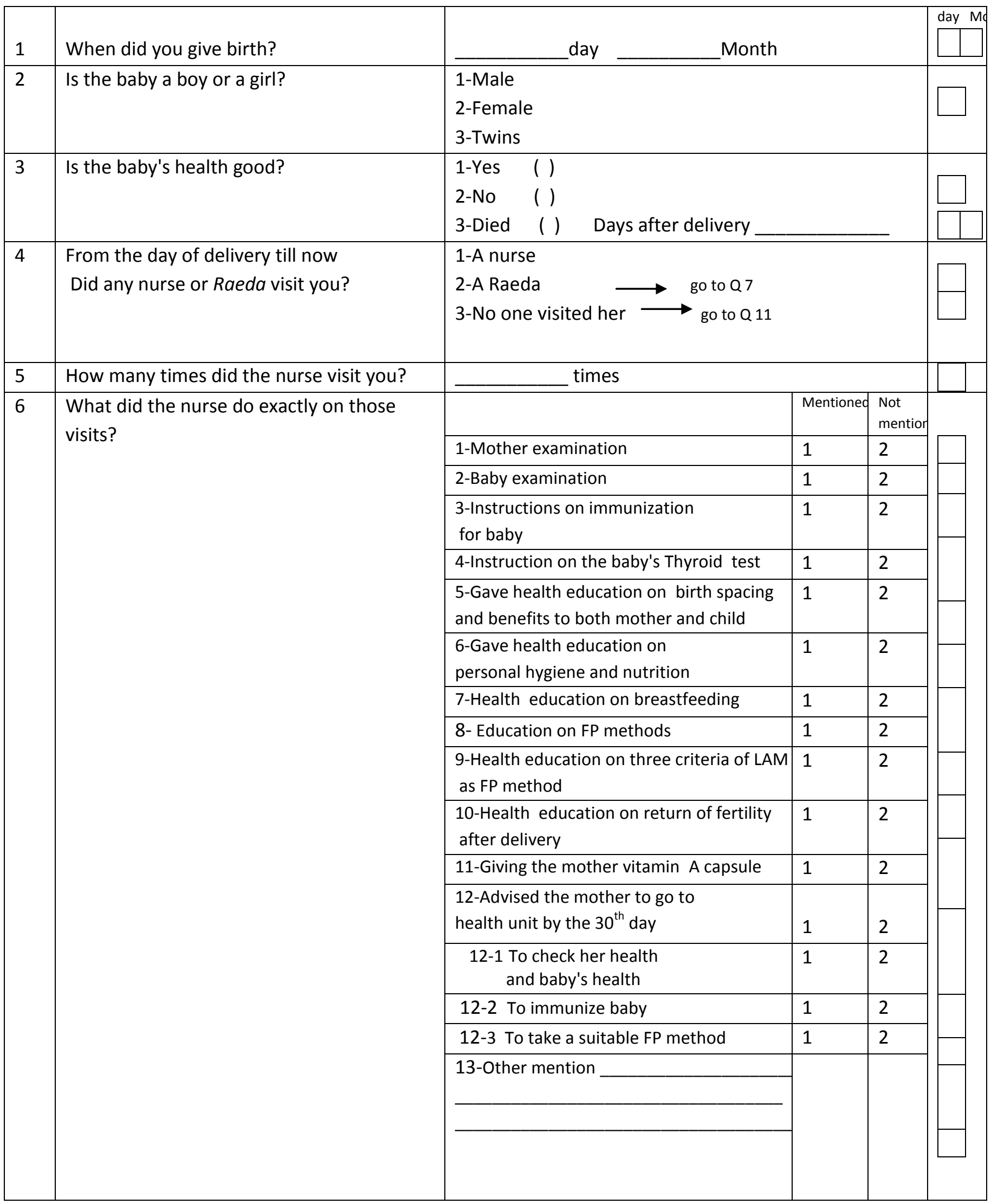




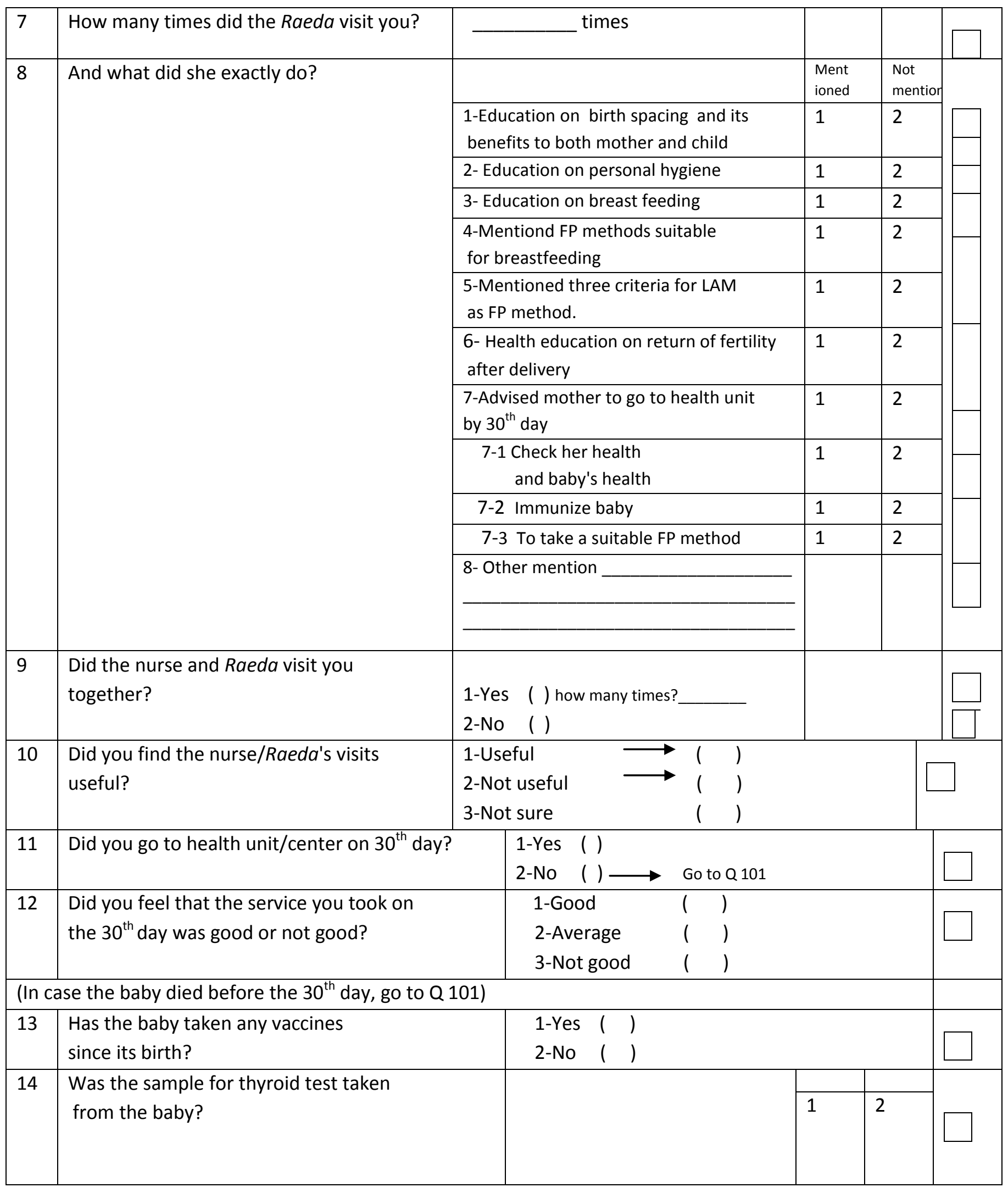




\section{Birth spacing:}

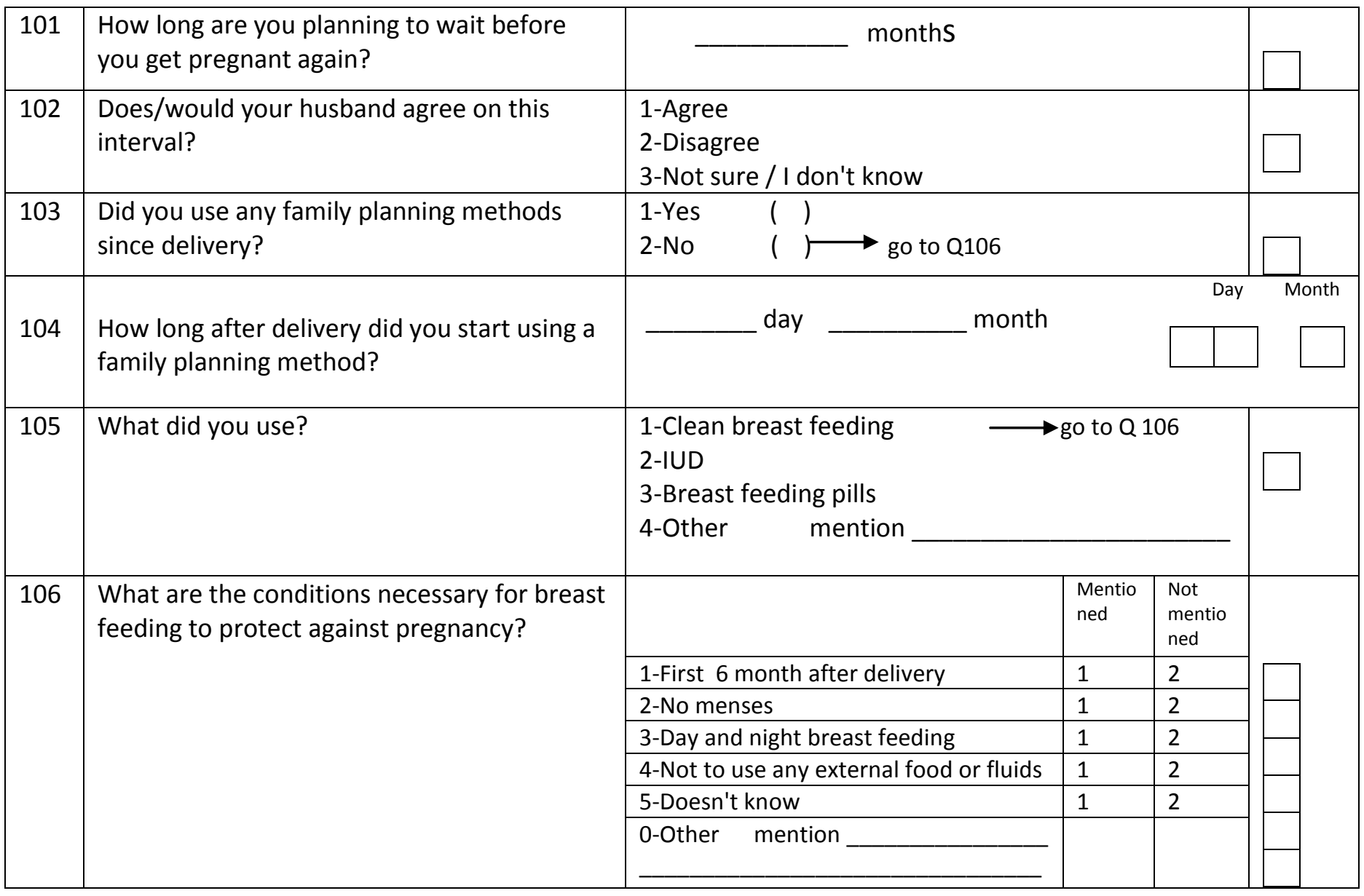

Thank you.

Data collector's comments 
Annex 5: Personal evaluation checklist list for monitoring of family planning compliance

Governorate:

District:

Supervisor:

Mark selected answer:
Name of Health Clinic:

Date:

Name of doctor/nurse:

\begin{tabular}{|c|c|c|c|}
\hline No. & Statements to be answered & Yes & No \\
\hline 1. & $\begin{array}{l}\text { Presence of target or quota for FP clients that should be achieved } \\
\text { each month }\end{array}$ & & \\
\hline 2. & $\begin{array}{l}\text { The presence of financial incentive for service provider to encourage } \\
\text { FP clients to use a specific FP method }\end{array}$ & & \\
\hline 3. & $\begin{array}{l}\text { The presence of financial incentive for FP clients to encourage them } \\
\text { to use a specific FP method }\end{array}$ & & \\
\hline 4. & $\begin{array}{l}\text { Depriving the client from receiving health services for not accepting a } \\
\text { specific family planning method }\end{array}$ & & \\
\hline 5. & The health clinic has a poster on different choices of FP methods & & \\
\hline 6. & The nurse acquainted the client with all the FP methods available & & \\
\hline 7. & $\begin{array}{l}\text { The nurse informed the client about FP methods side effects and how } \\
\text { to deal with them }\end{array}$ & & \\
\hline 8. & $\begin{array}{l}\text { The service provider imposed/convinced the client of using a } \\
\text { particular FP method }\end{array}$ & & \\
\hline 9. & All FP methods are available at the health clinic & & \\
\hline
\end{tabular}


Annex 6: Integration of family planning services into maternal and child health services to achieve healthy timing and spacing of pregnancies

\author{
Workshop schedule
}

April 16-18, 2011

Air Defense House

Day 1: Saturday, $16^{\text {th }}$ of April, 2011

9:00-9:30 Registration

9:30-10:00 Opening ceremony

10:00 - 11:30 Healthy timing and spacing of pregnancy

Discussion

11:30-11:45 Coffee break

11:45 - 1:00 Scaling up of integration of family planning services with maternal and child health services to achieve healthy timing and spacing of pregnancies: sharing the experience of Assiut and Sohag

1:00-1:15 Coffee break

1:15 - 3:15 Health education in antenatal care visits

Lessons learned from Assiut and Sohag

3:30 Lunch

Day 2: Sunday, $17^{\text {th }}$ of April, 2011

9:00 - 11:00 Postpartum Home visits

Lessons learned from Assiut and Sohag

Discussion

11:00-11:15 Coffee break

11:15 - 1:15 Providing integrated services at Day 30 visit to the clinic

Lessons learned from Assiut and Sohag 


$\begin{array}{ll} & \text { Discussion } \\ 1: 15-1: 30 & \text { Coffee break } \\ 1: 30-3: 30 & \text { Post-partum contraception } \\ 3: 30 & \text { Lunch }\end{array}$

Day 3: Monday $18^{\text {th }}$ of April, 2011

9:00 - 10:30 Informed choice in family planning

10:30 - 10:45 Introduction to working groups

10:45-11:00 Coffee break

11:00-1:45 Working groups to develop On the job training \& Monitoring and supervision plans

Group presentations

1:45-2:00 Closing remarks

2:00 Lunch 


\section{Annex 7:}

- Birth spacing flier
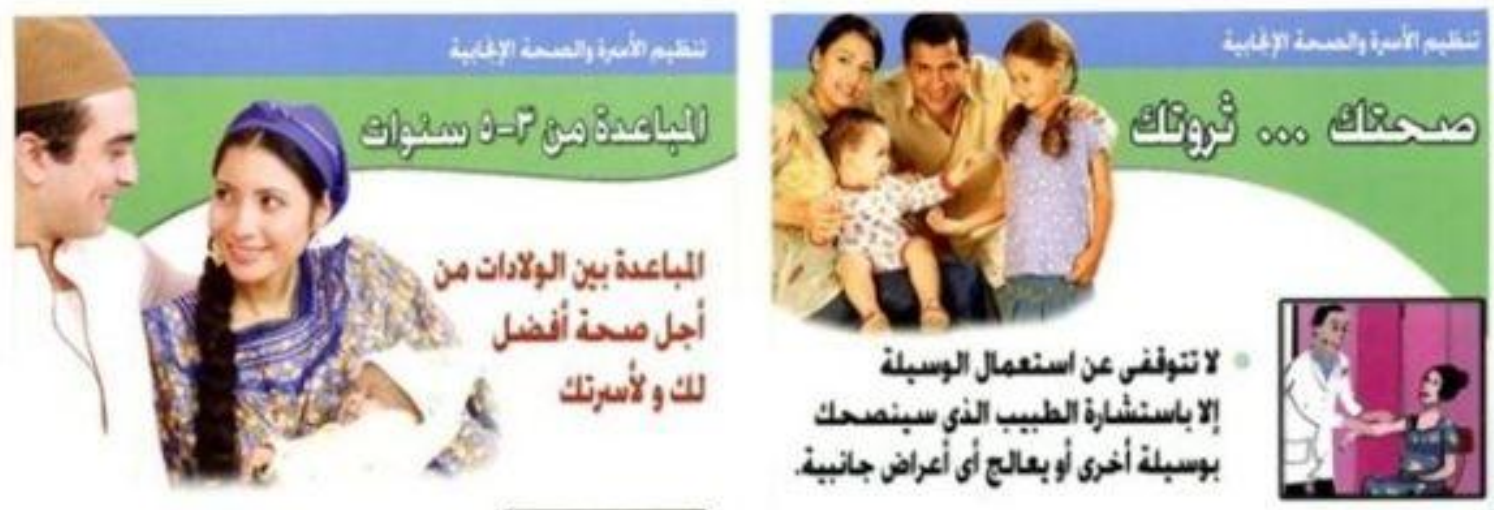

بنصيح باسنخدام وسيلة لنفظيه الأسرة بعد الطفل الأول لفزرة لاتفل عن

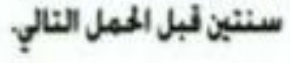

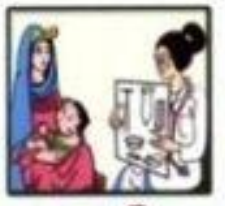
- بكن اسنخدام وسبلة لنتظبم الأسرة: خلال الأربعين بوم الأولى بعد الولادة والطبيب سبساعدك في اختبار

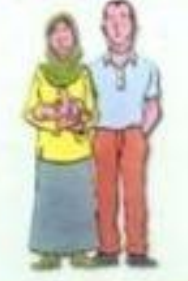

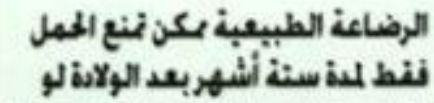
كانت رضاعذ مطلفة (عند الطلب لبلا لو نهارا و بسون إضافات غذائية) ومع
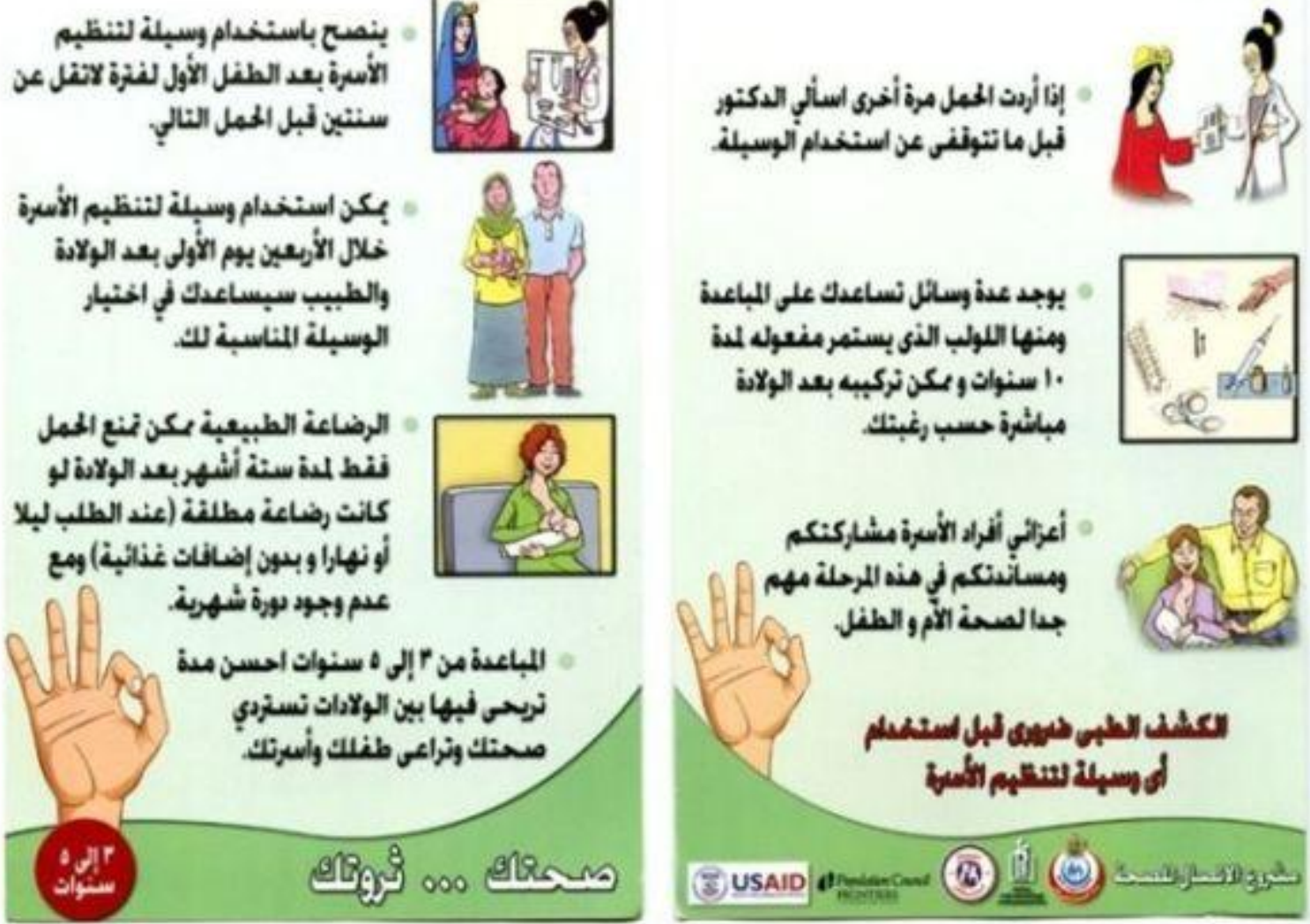

إذا أردث المعل مرة أخرى اسألب الدكتور. نبل ما تنوافنى عز اسنخدام الوسبلذ.

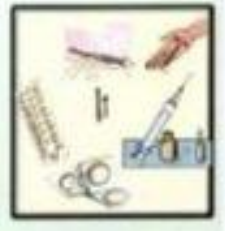

- أعزائب أفراد الأسرة مشاركتكم ومساتدنكم في منه المرحلة مهم الإنم جدا لصحة الآمر والطفل.
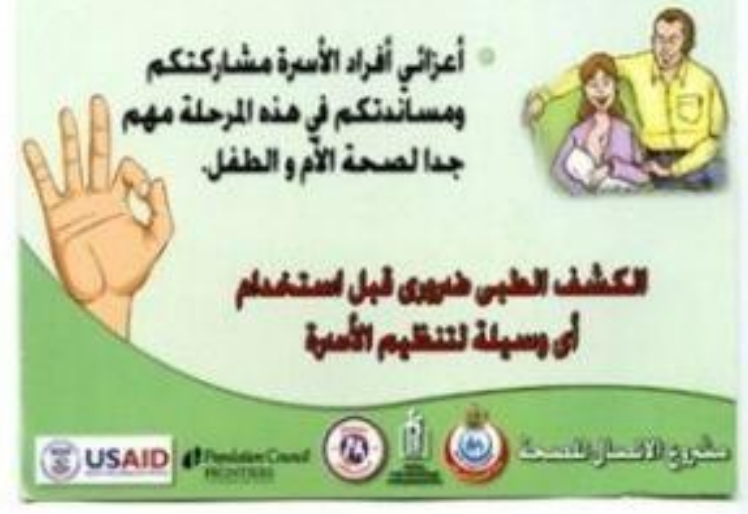


\section{- LAM Frequently Asked Questions sheet}

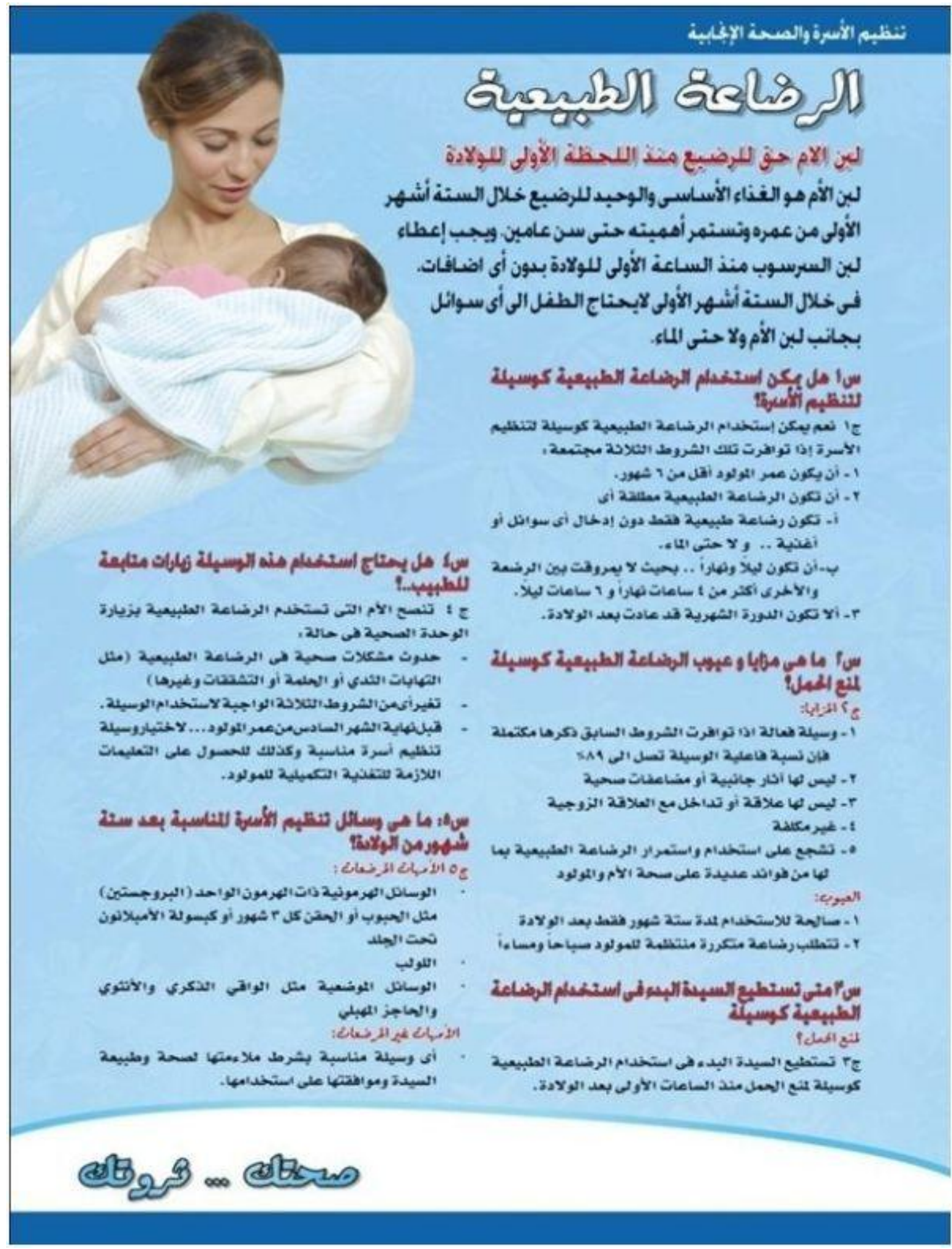




\section{- Breastfeeding / LAM flier}
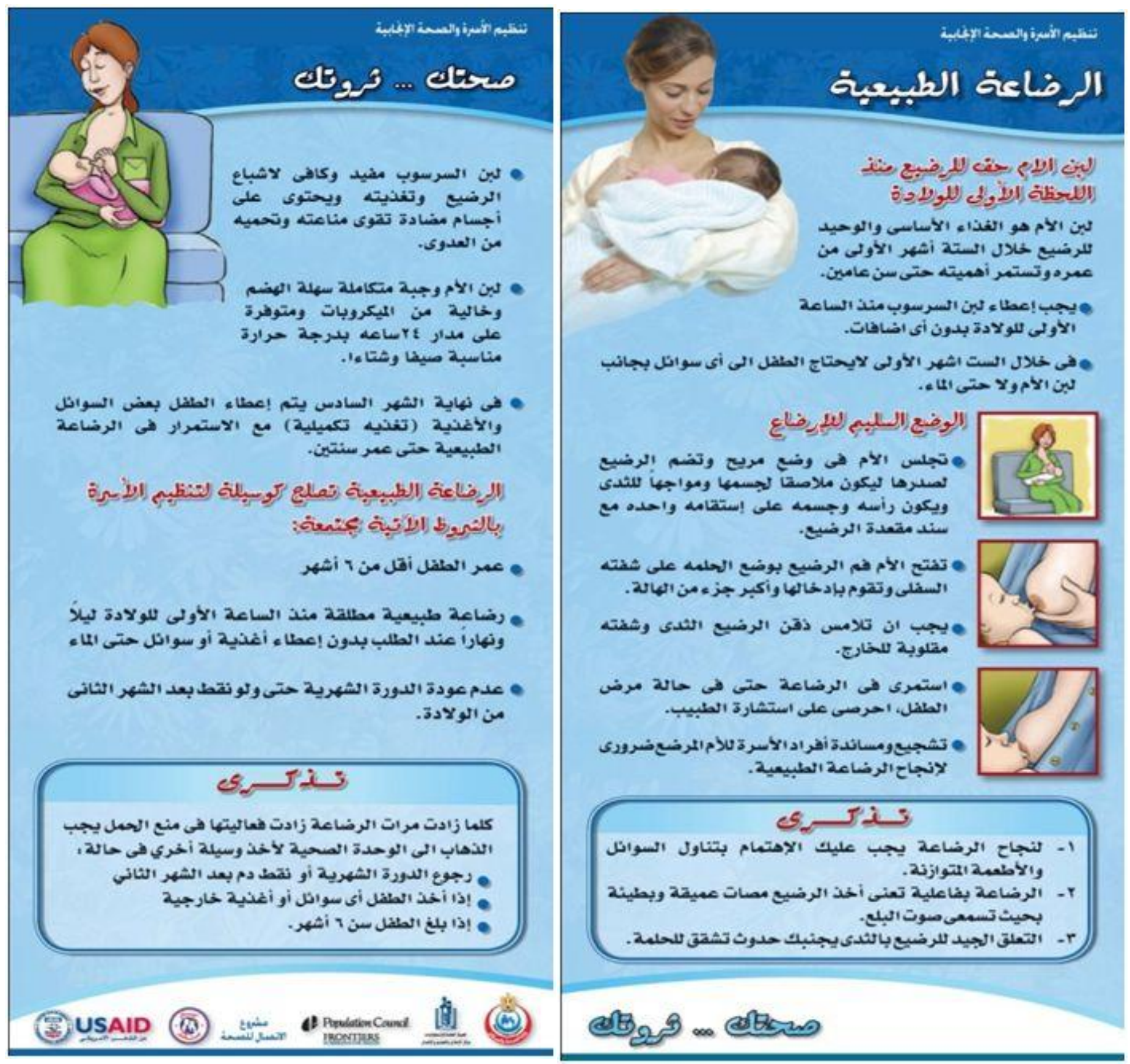
- Day $\mathbf{4 0}$ visit wall chart

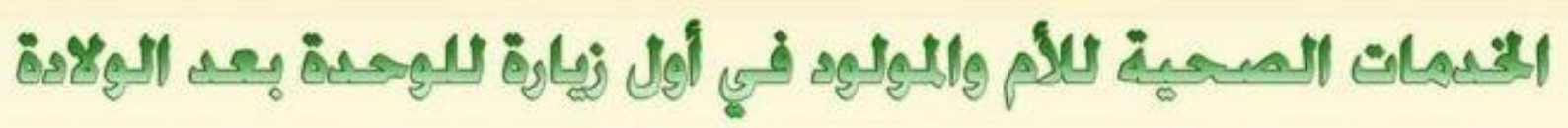

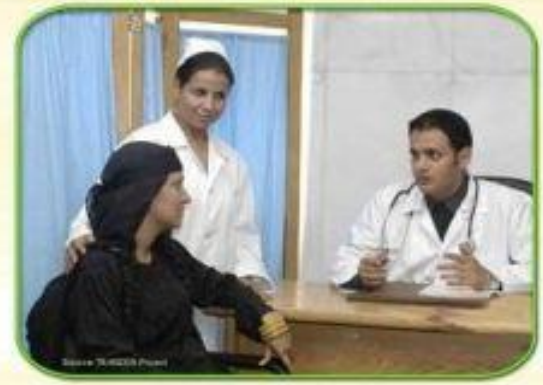

ه الكشف على السيدة والمولود

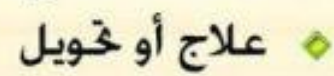
ه مشـورة صحية إو خويلة ه إعطاء وسيلة لتنظيم الأسرة
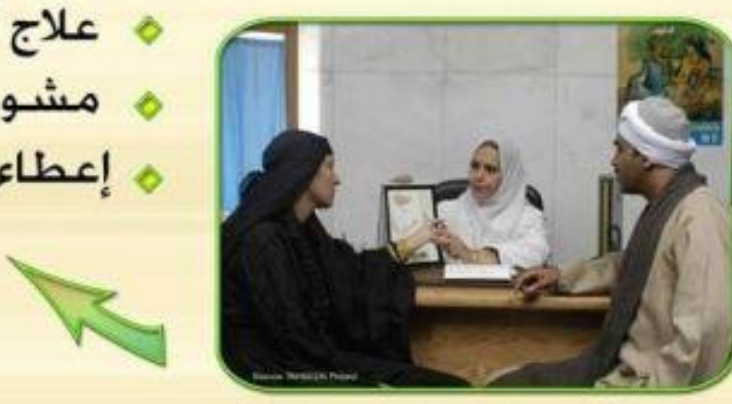

$$
\text { مشـورة تنظيـم الأسـرة }
$$

$$
\text { USAID }
$$
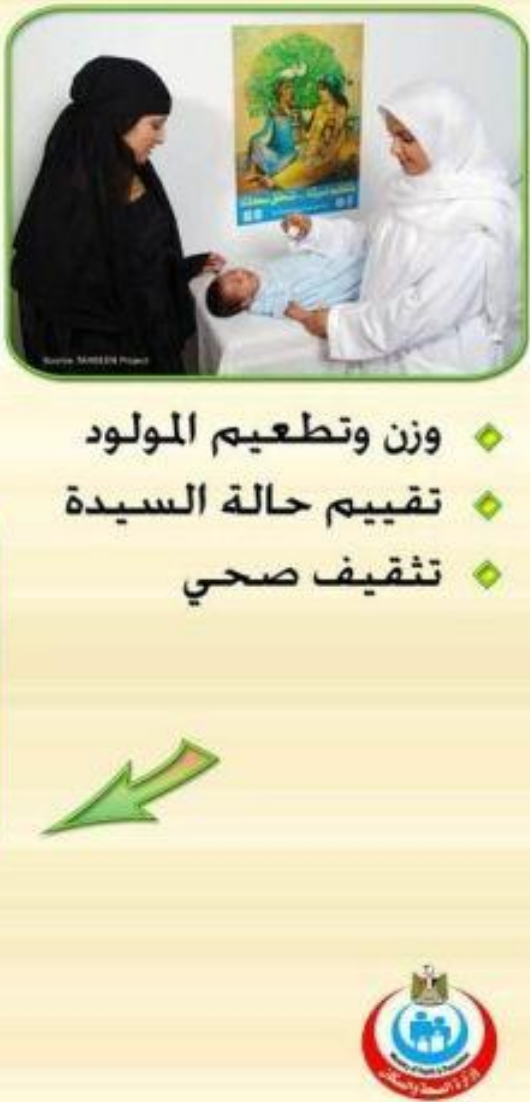
- Postpartum visits manual for nurses and RRs

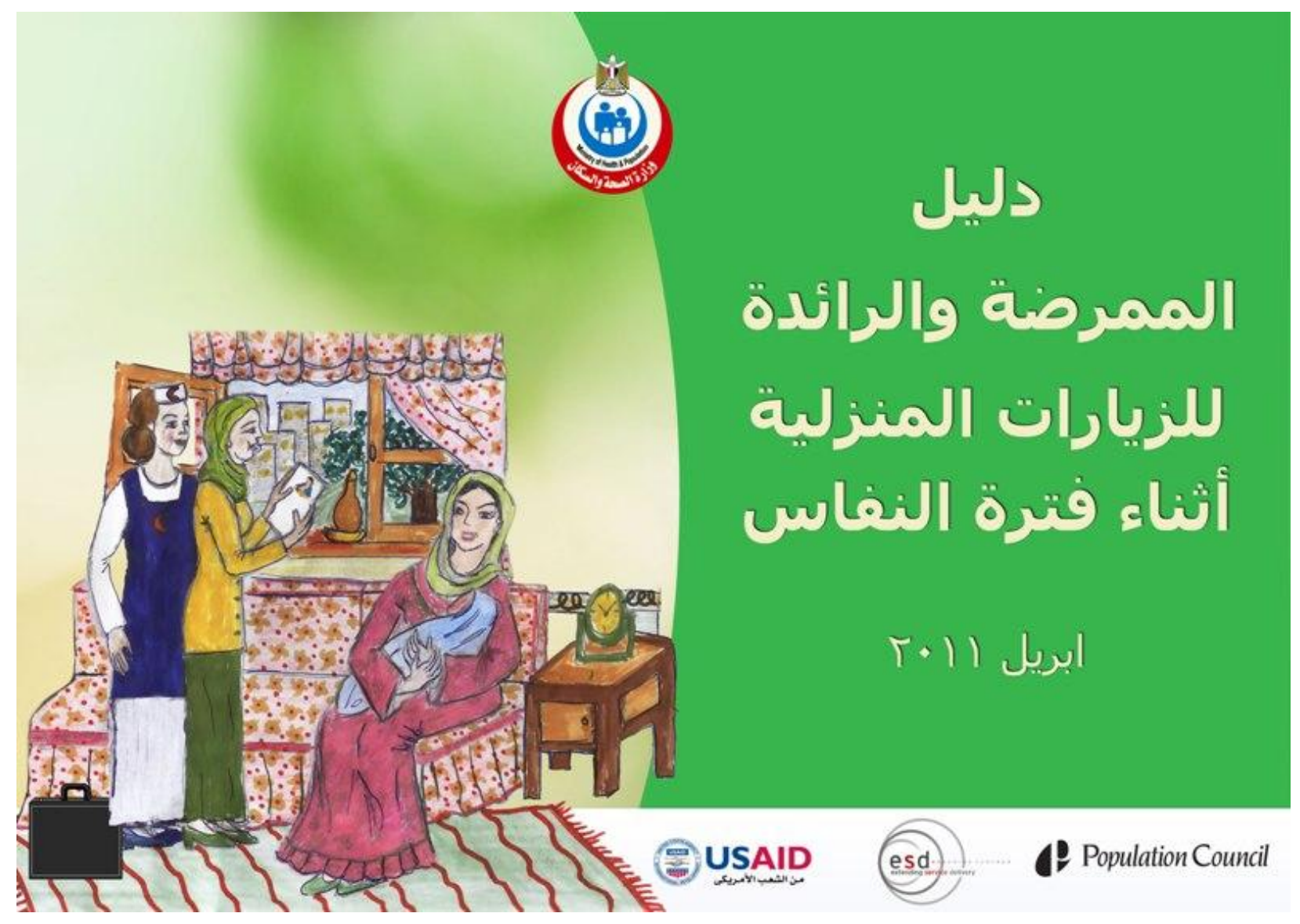


- Poster for counseling clients about birth spacing

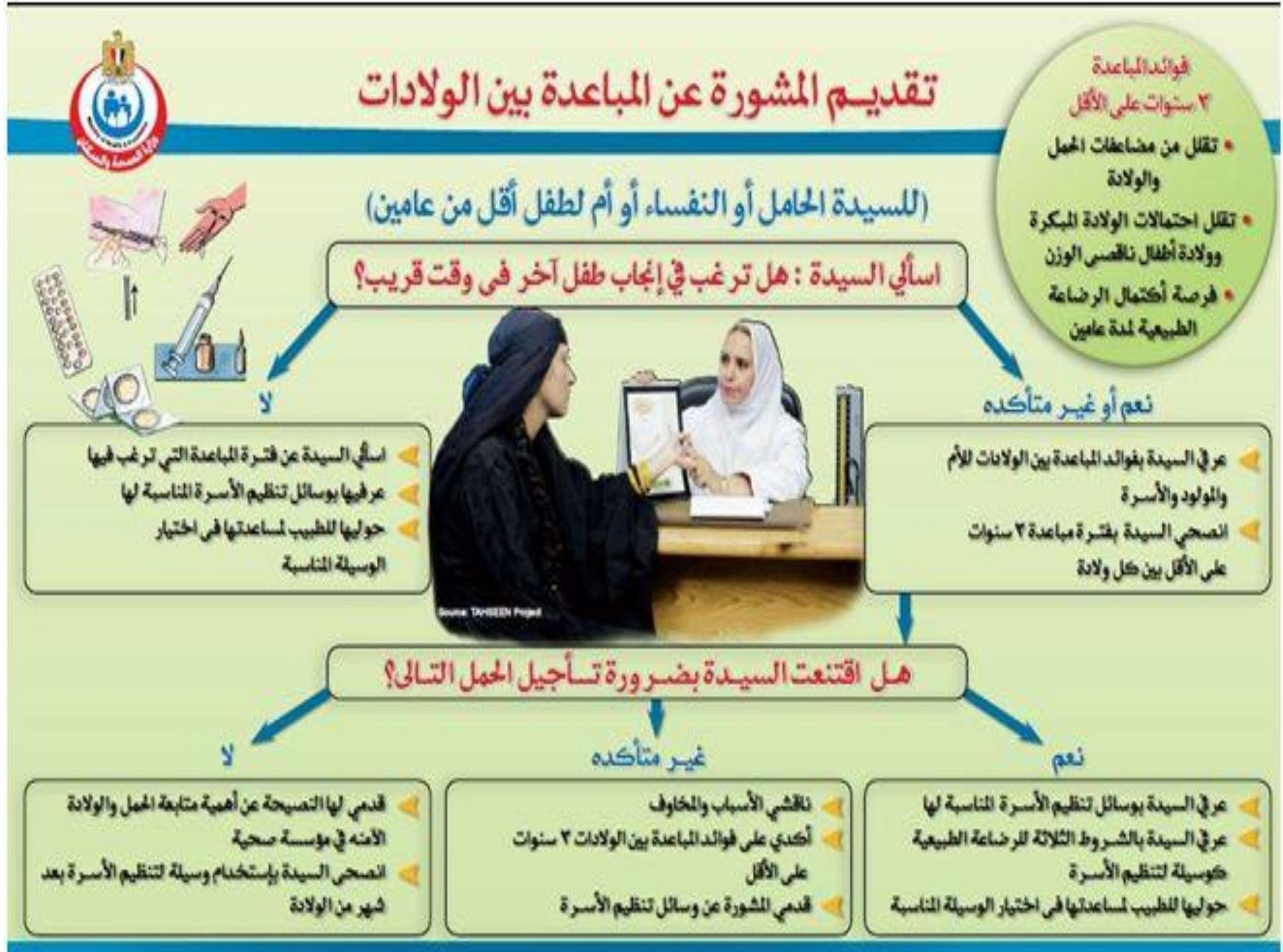

(2) USAID

Population Council

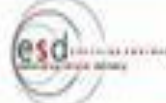

